\title{
Social Network Analysis of Public Administration Articles in Korea
}

\author{
Young-Chool Choi and Ji-Hyun Jang \\ Chungbuk National University, Korea \\ Sangmyung University, Korea \\ Corresponding author: ycchoi@cbu.ac.kr
}

\begin{abstract}
This paper aims to examine an overlooked area, the role of public administration and policy as a contributor to Korean national development using a social network analysis of public administration papers published in Korea. In addition, it suggests some future directions as to what Korean public administration system has to do both in the present and in the future. Korea has achieved an unprecedented ropid economic growth since 1948 when the Korean government was established. Nowadays, the developmental process which Korea has experienced has become a mode for other developing countries. However, there has been a dark side to this proces together with the light side associated with rapid economic development. These dark-side aspects inctude a gap between haves and have-nots, the gap between rural and yrban areas, and social polarization. The analysis results show that to overcome these obstacles, the Korean government should make great efforts by coordinating policy abjectives, policy priorities, policy tools, and the role of public administration, as KGreg soyermments have done in the past in order to attain the high rate of economic growth that has prevailed up until now.
\end{abstract}

Keywords: Korean public administration, social network analysis, Korean policy

\section{Introduction}

This paper is to examine an overlooked area, the role of public administration and policy as a contributor to Korean national development, from a historical point of view. In addition, it suggests a number of future directions, by following which the various challenges Korea might overcome that is confronting it. This paper begins by analysing articles published between 1967 and 2015 by the Korean Public Administration Review, the journal of the Korean Association of Public Administration, the academic association promoting studies of public administration and policy in Korea, with a view to identify the major issues relating to public administration and policy during a number of historical periods. It is -expected that this analysis will provide us with crucial information concerning which public administration and policy issues were raised at specific times and noy they were dealt with. This paper then offers a historical overview (again by period) of key practices and systems via which problems and issues relating to public administration and policy were addressed; and, finally, this paper puts forward a number of policy and theoretical suggestions as to how Korea might advance towards a high level of proficiency in public administration and policy. 


\section{Public Administration and Policy}

\subsection{Relationships between Public Administration and Policy}

Before discussing the role of public administration and policy from a historical point of view, it is essential to define the two terms 'public administration' and 'policy', and to delineate the relationships between the two.

There are many different definitions of public administration, but behind them all is a conception of it as a series of activities concerned with the formulation, implementation and evaluation of government policy, and also as an academic discipline that studies policy-related issues. Its fundamental goal is to advance the policy process, ranging from policy formulation to policy evaluation and the associated management issues, so that the government can function effectively. Hence, public administration is centrally concerned with the organization of government policies and programmes, as well as with the behaviour of those officials (usually non-elected) who are formally responsible for thetr performance. Public policy can be defined as government actions undertaken by the executive branches of the state with regard to a variety of public issues. Accordingly, the relationship between public administration and policy suggests that the former is a series of supportive actions aimed at formulating, implementing and evaluating thelatter, which are government actions undertaken to resolve public issues.

\subsection{Importance of Public Administration and Poliey}

Even though the complex relationships between publicadministration and public policy cannot be completely delineated clearly because they overlap in practice, public administration and public policy play acrucial role in Rational development, since public administration is primarily concerned with the management of public policies, the translation of politics into the day to-day reality of citizens, and the behaviour of government employees involved in the policy process.

\subsection{Analytical Framework}

Figure 1 presents the analytical framework within which the research question considered in this paper is addressed.

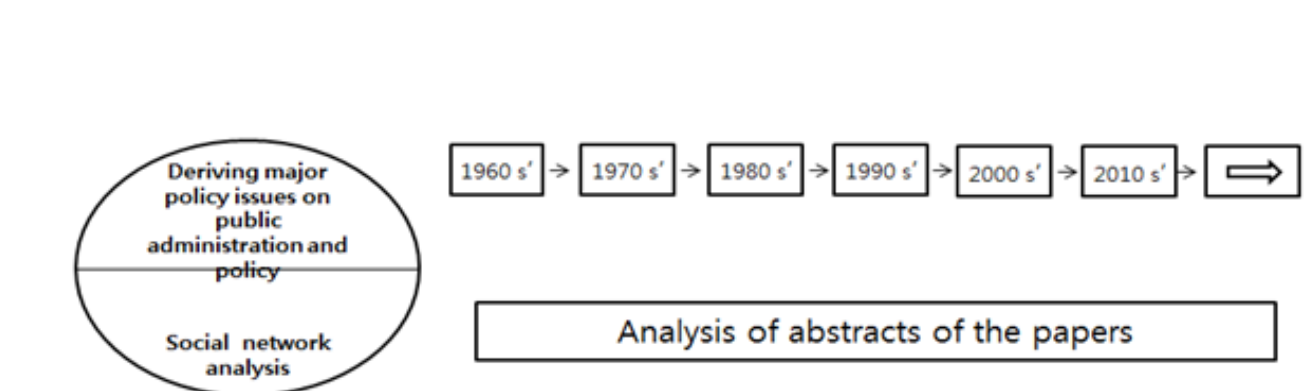

Figure 1. Analytical Framework

As indicated above, the research question here is to find major issues regarding Korean public administration and policy from a historical point of view. Major issues relating to public administration and policy are addressed via the social network analysis method. As a means of doing this, the papers included in the Korean Public Administration Review are analysed. The total number of papers published by the journal between 1967, when the Association began publishing, and 2015 is 1,612 . The number of papers to be analysed per period is shown in Table 1. 


\section{Table 1. Number of Papers to be Analysed per Period}

\begin{tabular}{|c|c|c|c|}
\hline Time period & Number of papers & Number of volumes & \\
\hline $1967-1969$ & 44 & $3($ vols $1-3)$ & \\
\hline $1970-1979$ & 123 & $10($ vols $4-13)$ & \\
\hline $1980-1989$ & 185 & $10($ vols $14-23)$ & \\
\hline $1990-1999$ & 560 & $10($ vols $24-33)$ & \\
\hline $2000-2010$ & 448 & $10($ vols 34-43) & \\
\hline $2010-2015$ & 252 & $6($ vols $44-49)$ & \\
\hline Total & 1,612 & & \\
\hline
\end{tabular}

In this analysis the abstract of every paper are examined, in order to identify keywords, and the characteristics of the networks containing them, relating to public administration and policy. By this means, the issues that were prevalent or dominant in the journal during each period are identified and the laws and institutions that were introduced in each period are described

\section{Major Issues Regarding Public Administration and Policy}

The social network analysis of the abstract of the papers included in these journals is shown in Table 2.

Table 2. Major Policy Issues Identified for Each Period

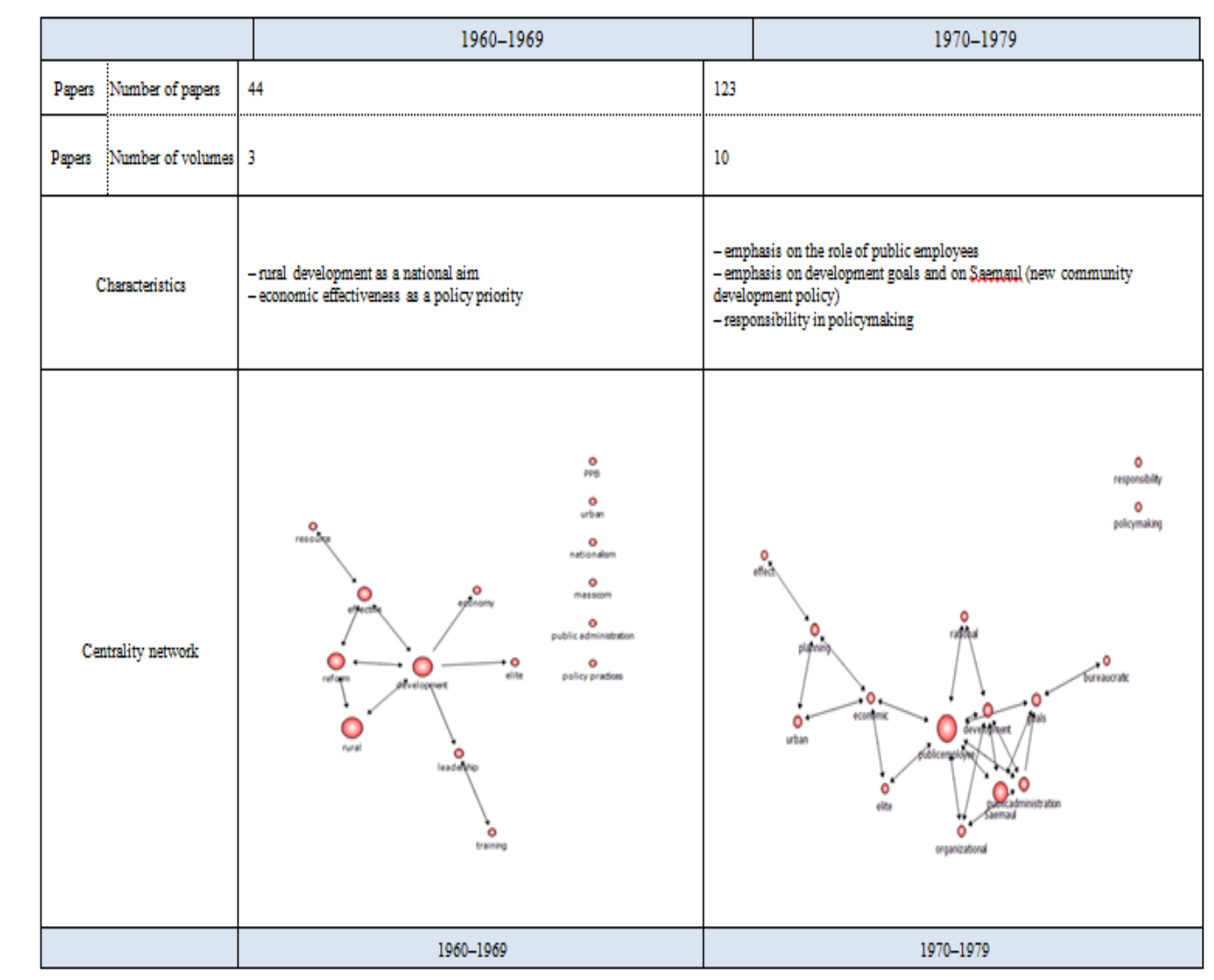




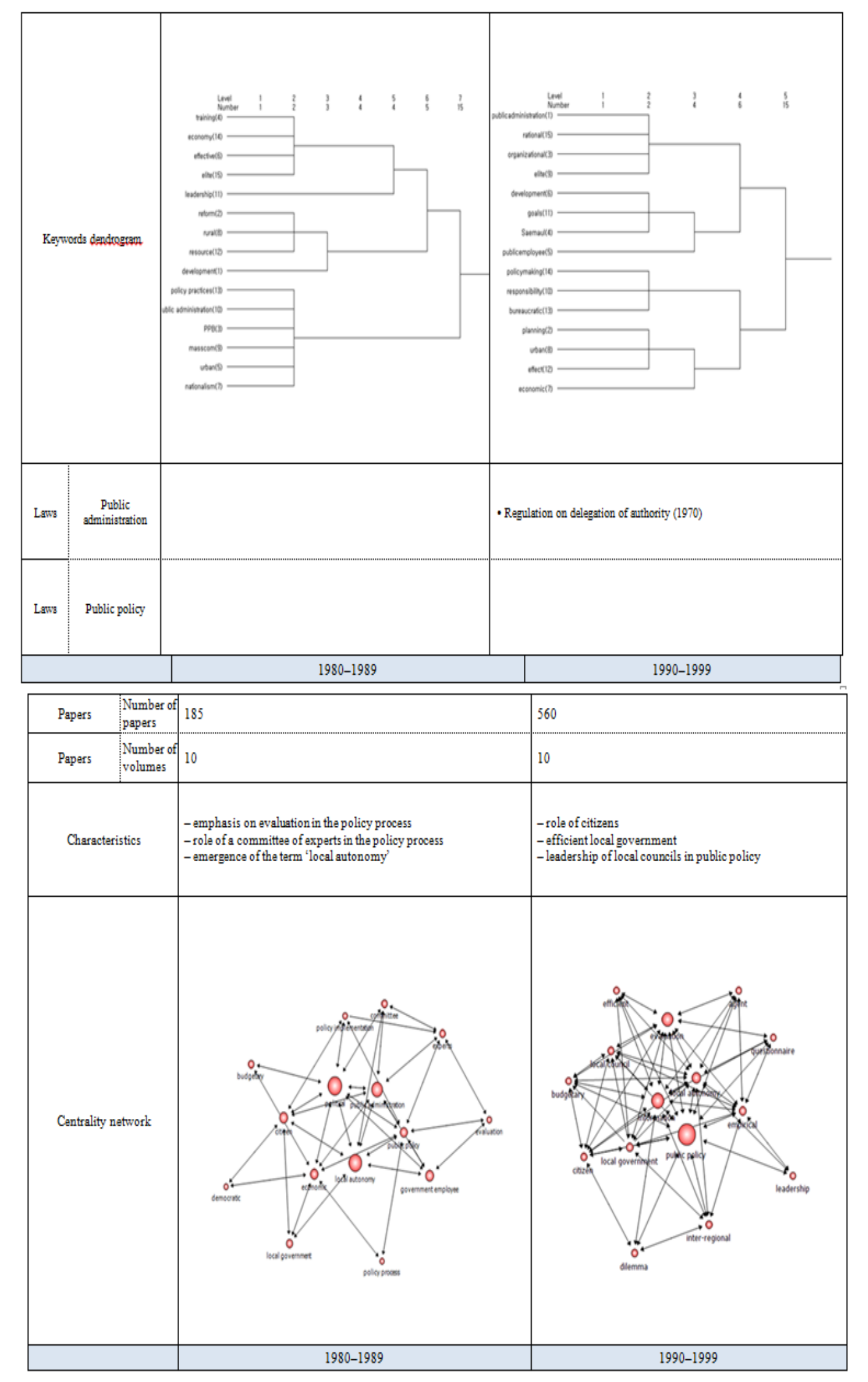




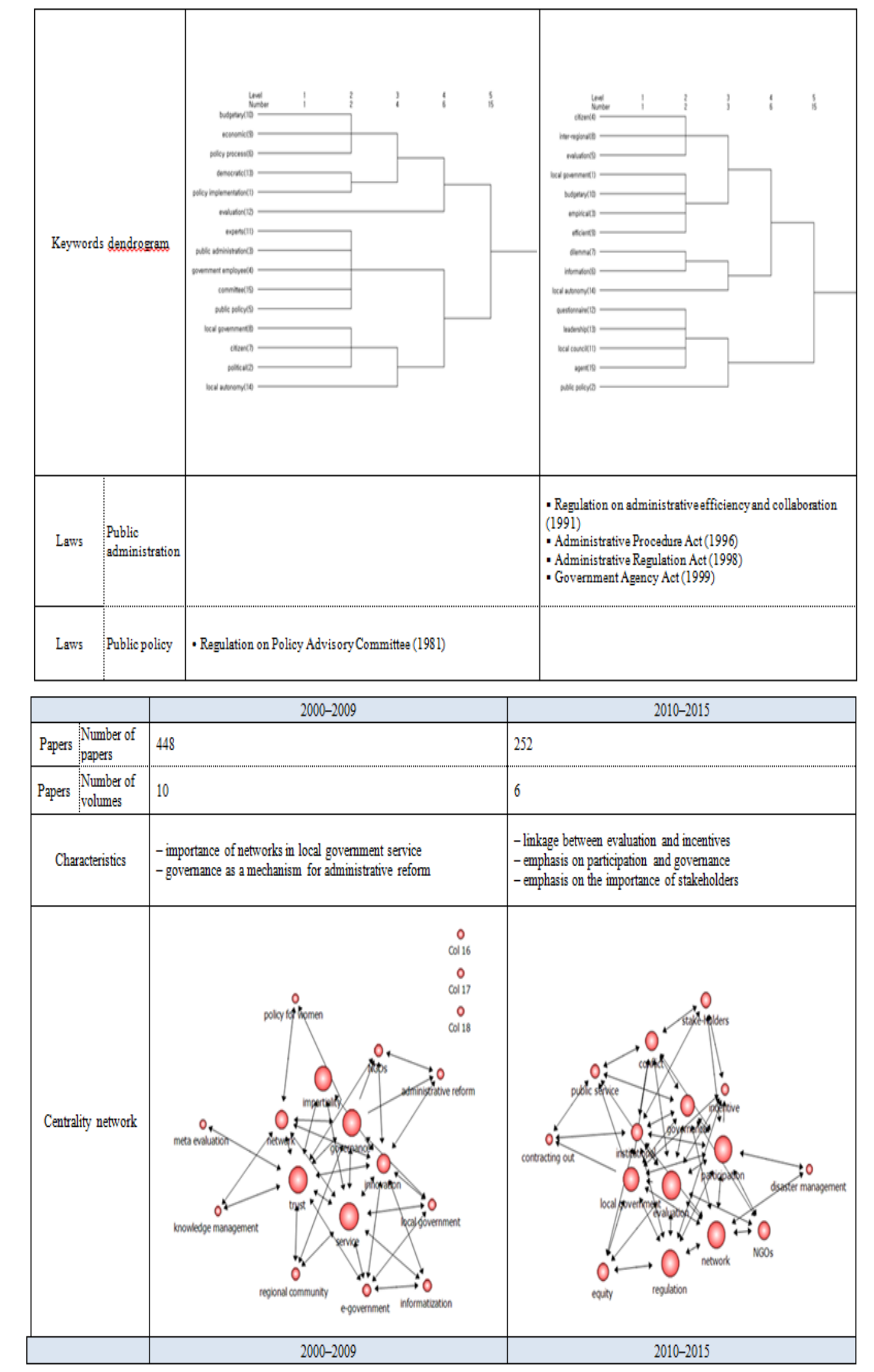




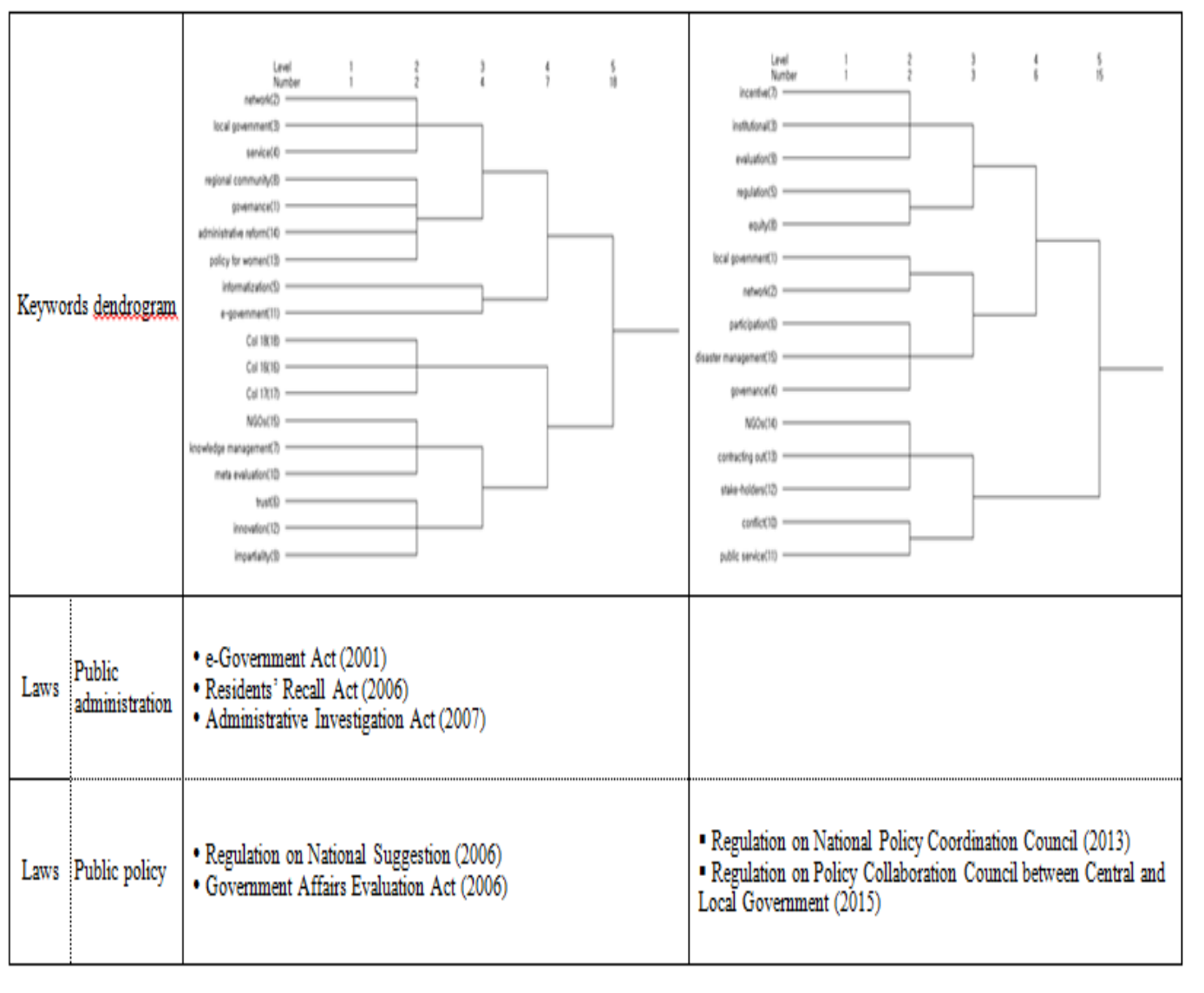

The analysis results may be sumnarized as follows. In the 1960s, rural development became the chief national aim and economiceffectiveness was regarded as a policy priority. During the period 1960-69, it is believed, there were no significant or remarkable regulatory actof public administration and policy. In the 1970s, by contrast, the role of public employees was emphasized along with development goals, and accordingly the Saemaul policy (new community development policy) appeared to gain traction. In the 980 s the term 'evaluation' emerged, and it seems to have been at this time that the evaluation system was adopted as part of the policy process. In this period, too, the role of a committee of experts was seen as important in terms of the democratic policy process. Likewse, the term 'local autonomy' was prevalent, implying that systems of local autonomy were being debated. In the 1990s, the role of the citizen was seen as important in the policy process, and local government efficiency also became a muchdebated and controversial issue. In the same context, local council leadership was assumed to be an important issue in terms of the policy process. In the 2000s, by contrast, the terms 'network' and 'governance', which are still dominant today, emerged, the belief apparently having been that governance can be an effective mechanism in terms of administrative reform. Finally, in 2010, evaluation appears to be linked with incentives, and it is believed also that participation and governance are crucial in terms of both public administration and the policy process.

\section{Conclusion: the Way Forward}

Based on the social network analysis of the public administration articles in Korea, we can say that Korea has achieved unprecedented rapid economic growth since 1948 when the Korean government was established. Nowadays, the developmental process which Korea has experienced has become a model for other developing countries. However, there has been a dark side to this process together with the light side associated with rapid 
economic development. These dark-side aspects include a gap between haves and havenots, the gap between rural and urban areas, and social polarization. To overcome these obstacles, the Korean government should make great efforts by coordinating policy objectives, policy priorities, policy tools, and the role of public administration, as Korea's government have done in the past in order to attain the high rate of economic growth that has prevailed up until now.

\section{Acknowledgements}

This work was supported by the National Foundation of Research Grant funded by the Korean Government (NRF-2015S1A5B8046954).

\section{References}

[1] H. S. Choi, T. Y. Kim and J. D. Jung, "Service Delivery System of Advanced Countries", KAPA Research Report, (2008).

[2] D. Robert and J. Denhardt, "Public Administration: An Action Orientation", Belmont CA. Thomson Wadsworth, 6th edn, (2009).

[3] K. Donald and J. Fessler, "The Politics of the Administrative Process", Washington, DC. CQ Press, (2009).

[4] S. M. Kim, "The evolution of Korean Public Administration", KAPA Research Report (2008).

[5] T. Y. Kim, "New Theories of Korean Government", Seoul Dàeyoung Publishing, (2014).

[6] J. R. Lee and S. B. Park, "Theories of Policy Sciences", Seoul Daeyoung Publishing, (2005).

[7] J. S. Lee, "Understanding Korean Public Administration", Seoul: Daeyoung Publishing, (2013).

[8] J. B. McKinney and L. C. Howard, "Howard Public Administration: Balancing Power and Accountability", Westport, CT: Praeger, 2nd edn, (1998).

[9] M. J. Moon, "The evolution of the developmen al state and government capacity in Korea: achievements and challenges", In Park, K.W., Lee, W 1 and Lee, S. H.(ed.), "Understanding Korean Public Administration", N. Y.: Routledge, (2016), pp 11-33.

[10] R. Nakamura and F. Smallwood, "The Politics of Poticy Implementation", N.Y.: St. Martin's Press, (1980).

[11] K. K. Nam, "Policy Sciences", Seoul: Bummunsa (2012).

[12] L. M. Salamon, "The New Governance and the Tools of Public Action: An Introduction" (pp. 1-47) in Salamon, M. Lester (ed) "The Tools of Government: A Guide to the New Governance", Oxford University Press, (2002).

[13] World Bank, Statistic Database.

[14] H. Yoo, "Policy Implementation", Seoul Daeyoung Publishing, (2008).

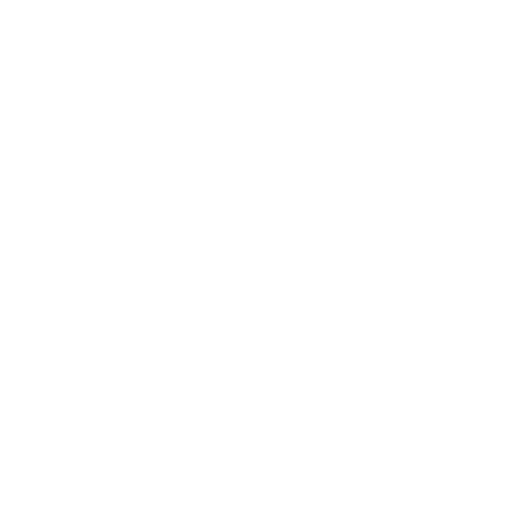


International Journal of Multimedia and Ubiquitous Engineering

Vol.11, No.12 (2016)

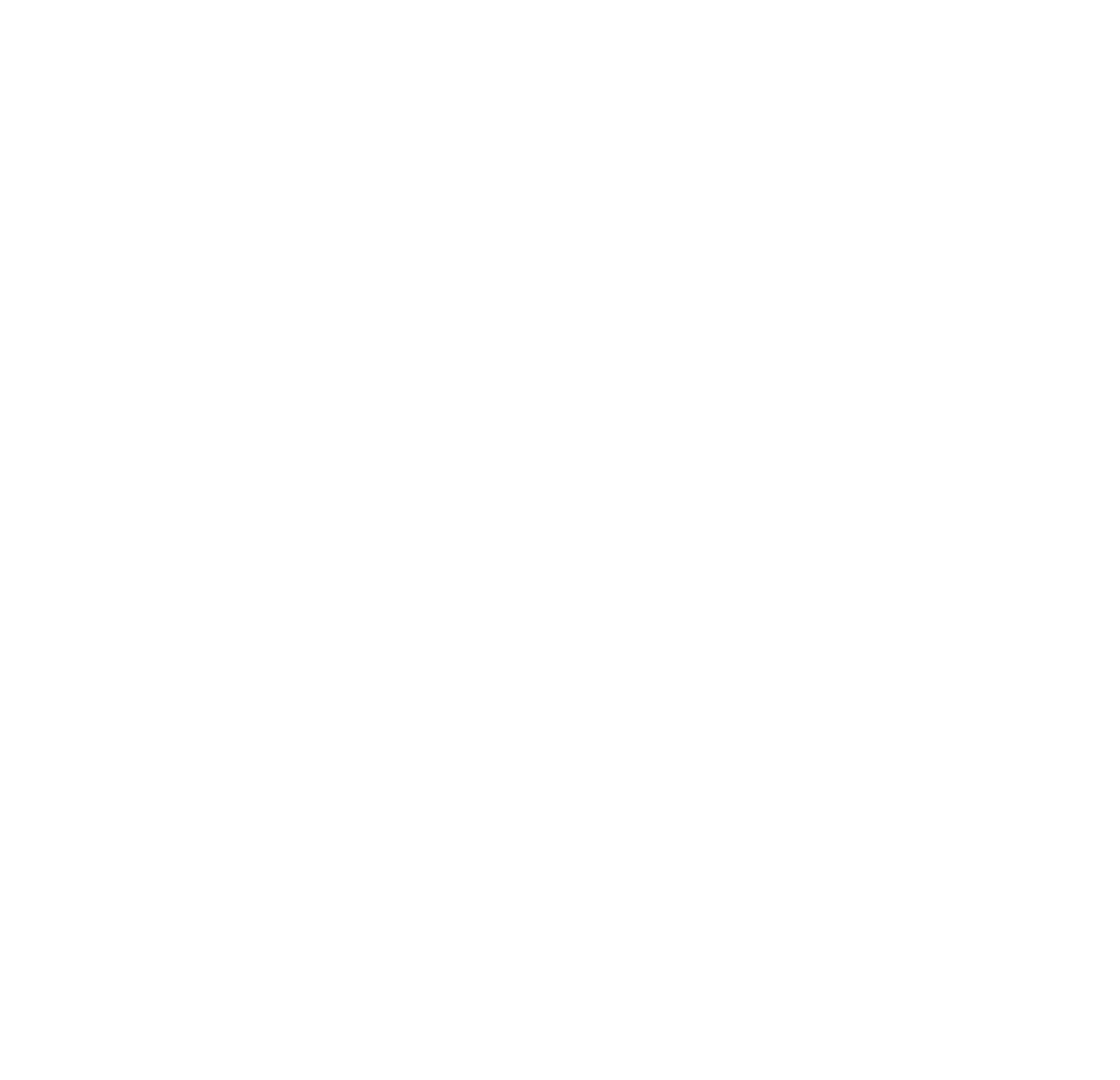

